\title{
Endoscopic Therapeutic Approach for Dysplasia in Inflammatory Bowel Disease
}

\author{
Sung Noh Hong \\ Department of Medicine, Samsung Medical Center, Sungkyunkwan University School of Medicine, Seoul, Korea
}

Long-standing intestinal inflammation in patients with inflammatory bowel disease (IBD) induces dysplastic change in the intestinal mucosa and increases the risk of subsequent colorectal cancer. The evolving endoscopic techniques and technologies, including dye spraying methods and high-definition images, have been replacing random biopsies and have been revealed as more practical and efficient for detection of dysplasia in IBD patients. In addition, they have potential usefulness in detailed characterization of lesions and in the assessment of endoscopic resectability. Most dysplastic lesions without an unclear margin, definite ulceration, non-lifting sign, and high index of malignant change with suspicion for lymph node or distant metastases can be removed endoscopically. However, endoscopic resection of dysplasia in chronic IBD patients is usually difficult because it is often complicated by submucosal fibrosis. In patients with dysplasias that demonstrate submucosa fibrosis or a large size ( $\geq 20 \mathrm{~mm}$ ), endoscopic submucosal dissection (ESD) or ESD with snaring (simplified or hybrid ESD) is an alternative option and may avoid a colectomy. However, a standardized endoscopic therapeutic approach for dysplasia in IBD has not been established yet, and dedicated specialized endoscopists with interest in IBD are needed to fully investigate recent emerging techniques and technologies. Clin Endosc 2017;50:437-445

Key Words: Inflammatory bowel disease; Dysplasia; Endoscopic resection

\section{INTRODUCTION}

Large population-based studies that include more than 1,000 patients with inflammatory bowel disease (IBD) have demonstrated that patients with long-standing IBD had a higher risk of colorectal cancer (CRC) than the general population, 2.7- to 5.7-fold and 2.1- to 5.6-fold higher than in those with ulcerative colitis (UC) and colonic Crohn disease (CD), respectively. ${ }^{1-4}$ Recent population-based studies have shown that the CRC risk in IBD patients is lower than previously thought, and the decreasing risk of CRC over the past 30 years might be a result of the improved therapies for patients with IBD. ${ }^{5}$

Received: August 21, 2017 Revised: September 21, 2017

Accepted: September 25, 2017

Correspondence: Sung Noh Hong

Department of Medicine, Samsung Medical Center, Sungkyunkwan University School of Medicine, 81 Irwon-ro, Gangnam-gu, Seoul 06351, Korea

Tel: +82-2-3410-3409, Fax: +82-2-3410-6983, E-mail: sungnoh.hong@samsung.com

(cc) This is an Open Access article distributed under the terms of the Creative Commons Attribution Non-Commercial License (http://creativecommons.org/ licenses/by-nc/3.0) which permits unrestricted non-commercial use, distribution, and reproduction in any medium, provided the original work is properly cited.
In patients with $\mathrm{UC}$, according to a meta-analysis, the estimated risk of CRC was 2.4-fold higher than that in the general population, depending on the duration, extent, and severity of inflammation. ${ }^{6}$ The risk of developing precursor lesions such as dysplasia or invasive cancer increases exponentially with disease duration. Histological or macroscopic pancolitis carries the highest risk, with no increased risk for patients with proctitis. The risk appears to increase about 8-10 years after diagnosis in patients with pancolitis (a 5- to 15-fold increase in risk) and at 15-20 years (3-fold) in those with left-sided colitis. ${ }^{7}$ The cumulative incidence of CRC in patients with pancolitis is estimated to be $5 \%$ to $10 \%$ after 20 years and $12 \%$ to $20 \%$ after 30 years of disease duration. ${ }^{8}$ Recent studies suggest that given a similar duration and extent of disease, patients with CD had a similar risk of dysplasia and cancer as patients with UC. A meta-analysis of population-based studies showed that the risk of CRC in patients with CD was increased to as much as 1.6-fold higher than that in the general population. ${ }^{9}$

Surveillance colonoscopy could allow earlier detection of CRC with a corresponding improved prognosis. ${ }^{10}$ Previously, dysplasia that develops in IBD was thought to be invisible, and 
total colectomy was inevitable to treat dysplasia in patients with IBD. Guidelines recommended obtaining 32 or more random biopsy samples from every segment of the colon during endoscopic surveillance. ${ }^{11}$ Despite procedures being vigorous for both the patients and endoscopists, the biopsy samples cover $<0.1 \%$ of the mucosal surface of the whole colon, and the random biopsy strategy appears to be inefficient. With the advances of endoscopic technologies and techniques, most dysplasias detected in IBD are visible and identifiable during surveillance endoscopy. ${ }^{12}$ Visualization of dysplasia in IBD patients allows for assessment of its morphology, border, surface features, size, and background mucosa. Therefore, endoscopists can decide regarding endoscopic resectibility, and endoscopic resection might be applicable. The current paradigm for diagnosis and treatment shifted from random biopsies and surgery to target biopsy and endoscopic resection. ${ }^{13}$

\section{IBD-ASSOCIATED COLORECTAL CARCINOGENESIS}

Sporadic CRC is caused by genomic instability, which results from multistep carcinogenesis, or the so--called adenoma-carcinoma sequence. Three distinct pathways of carcinogenesis have been described, namely chromosomal instability (CIN), microsatellite instability (MSI), and CpG island methylator phenotype (CIMP) pathways. Roughly $85 \%$ of sporadic CRCs are caused by CIN, and the remaining 15\% result from MSI; CIMP accounts for most of the MSI-positive/CIN-negative CRCs.

Many of the molecular changes responsible for sporadic CRC development also play a role in IBD-associated col- orectal carcinogenesis. CIN is the most frequently occurring form of genomic instability in IBD-associated carcinogenesis. However, in IBD-associated colorectal carcinogenesis, the alteration of adenomatous polyposis coli/beta-catenin signaling is infrequent, ${ }^{8}$ and p53 mutation is the initiating mutation in most lesions (Fig. 1). ${ }^{14}$ MSI covers approximately $10 \%$ to $15 \%$ of colitis-associated cancers, although the frequency of MSI in nondysplastic, inflamed epithelia is relatively high. ${ }^{8}$ Methylation of $\mathrm{CpG}$ islands in several genes is thought to precede dysplasia, is widespread in the mucosa of UC, and is becoming increasingly important as a mechanism contributing to the genetic alterations in IBD-associated CRC. ${ }^{15}$

In IBD, multifocal dysplastic lesions and cancer are common. ${ }^{14,16}$ The concept of field cancerization-the formation of a histologically indistinguishable area of clonally derived, mutant cells within the inflamed segment of the intestinal tract in IBD—-has been widely accepted. ${ }^{17}$ Molecular studies have provided strong evidence for the field cancerization theory. The same mutation spectrum in either p53 or K-RAS is detected across entire neoplastic lesions and in nondysplastic crypts, suggesting that the mutant clone(s) is involved in the field of IBD mucosa. ${ }^{14}$ Most field changes appear to be induced by chronic active inflammation, which implies key inflammatory events. Field cancerization in IBD means that once dysplasia is initiated in patients with IBD, the entire colon is at an increased risk of developing cancer. Therefore, field cancerization in IBD provides the rationale for the traditional approach, which involves total colectomy and an extensive histopathological evaluation for the identification of multiple dysplasia and cancer. However, total colectomy has potentially high morbidity and mortality rates.

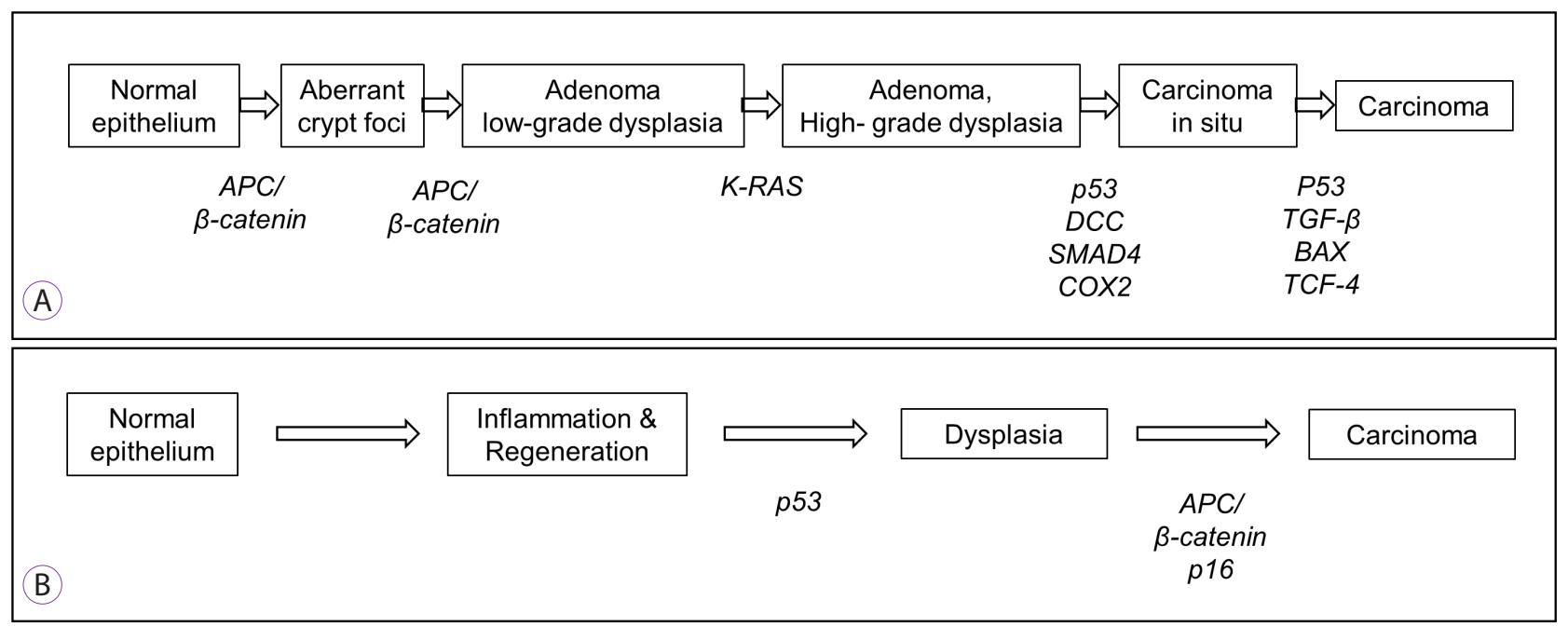

Fig. 1. Carcinoma sequence pathways. (A) Sporadic colorectal cancer: adenoma-carcinoma sequence. (B) Inflammatory bowel disease-associated colorectal cancer: dysplasia-carcinoma sequence, Adapted from Matkowskyj et al. ${ }^{8}$ 


\section{SCENIC CLASSIFICATION OF FINDINGS FROM PATIENTS WITH IBD ON COLONOSCOPIC SURVEILLANCE}

In the era of fiberoptic and early video endoscopy, studies indicate that $50 \%-80 \%$ of colitis-associated neoplastic lesions are not visible on endoscopy. ${ }^{18}$ Biopsies obtained from nodular mucosa, even random biopsies without definite visible endoscopic lesion, are useful for identifying dysplasia. In particular, biopsies obtained from a lesion or mass are often found to have cancer and are called "dysplasia-associated lesion or mass (DALM)".19 Endoscopic technologies have advanced, and the charge-coupled device (CCD) chips in standard-definition endoscopes produce signal images of 100,000 to 400,000 pixels. $^{20}$ Although flat dysplasia is difficult to delineate, DALM can be identified as a polyp, non-polypoid, or mass shape during colonoscopic surveillance in IBD patients. DALM was subdivided into "adenoma-like" and "non-adenoma-like" lesions because of endoscopic appearance. Adenoma-like DALM, regardless of the grade of the dysplasia or location of the lesion (i.e., inside or outside areas of established colitis), can be managed with endoscopic resection. ${ }^{21}$ With further advances in CCD technologies and endoscopic techniques, including high-definition white-light endoscopy and chromoendoscopy, invisible dysplasia accounts only for a few (10\%) patients diagnosed as having dysplasia. ${ }^{22}$ Chromoendoscopy with indigo-carmine or methylene blue can be highly useful to identify a flat mucosal lesion and delineate the margin and surface features of dysplasia. High-definition endoscopes produce signal images of 850,000 to $>1$ million pixels, and brighter lighting allows endoscopists to visualize the colonic mucosa in greater detail than standard-definition endoscopes. Therefore, patients with endoscopically invisible dysplasia (confirmed on pathological examination) are referred to an endoscopist with expertise in IBD surveillance using high-definition colonoscopy and pancolonic chromoendoscopy. ${ }^{13}$

In 2015, Surveillance for Colorectal Endoscopic Neoplasia Detection and Management in Inflammatory Bowel Disease Patients: International Consensus Recommendations (SCENIC) issued an international consensus statement. ${ }^{13}$ This statement abandoned the term DALM and instead described visible and invisible dysplasia. Visible dysplasia was defined as dysplasia identified on targeted biopsies from a lesion visualized on colonoscopy, and invisible dysplasia was referred to as dysplasia identified on random (non-targeted) biopsies of colonic mucosa without a visible lesion. Visible dysplasia was subdivided into polypoid and non-polypoid based on the Paris classification. The description of visible dysplasia included the addition of terms for ulceration and lesion border (Fig. 2). ${ }^{13}$

\section{PRE-POLYPECTOMY ASSESSMENT}

When a lesion suspected to be dysplasia is found during surveillance, the endoscopist should assess whether the lesion location is within or outside an area of known colitis. Visible dysplasias detected in the colonic area that are not involved with colitis can be managed as sporadic adenomas, with the standard endoscopic removal technique and post-polypectomy surveillance recommendations. If visible dysplasia is identified in an area of known colitis, its endoscopic resectability should be assessed before attempting to remove it.

\begin{tabular}{|c|c|c|c|}
\hline Classification & & Endoscopic appearance & Definition \\
\hline \multirow[t]{2}{*}{ Polypoid } & Pedunculated & & Lesion attached to the mucosa by a stalk \\
\hline & Sessile & $7 \$ 2.5 \mathrm{~mm}$ & $\begin{array}{l}\text { Lesion not attached to the mucosa by a stalk: entire base is } \\
\text { contiguous with the mucosa }\end{array}$ \\
\hline \multirow[t]{3}{*}{ Non-polypoid } & Superficial elevated & 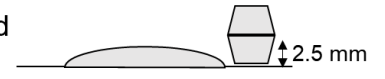 & $\begin{array}{l}\text { Lesion with protrusion but }<2.5 \mathrm{~mm} \text { above the lumen (less } \\
\text { than the height of the closed cup of a biopsy forceps) }\end{array}$ \\
\hline & Flat & & Lesion without protrusion above the mucosa \\
\hline & Depressed & & $\begin{array}{l}\text { Lesion with at least a portion depressed below the level of } \\
\text { the mucosa }\end{array}$ \\
\hline \multirow{2}{*}{$\begin{array}{l}\text { General } \\
\text { descriptors }\end{array}$} & Ulcerated & \multicolumn{2}{|c|}{ Ulceration (fibrinous-appearing base with depth) within the lesion } \\
\hline & $\begin{array}{l}\text { Border : Distinct } \\
\text { Indistinct }\end{array}$ & \multicolumn{2}{|c|}{$\begin{array}{l}\text { Lesion's border is discrete and can be distinguished from surrounding mucosa } \\
\text { Lesion's border is not discrete and cannot be distinguished from surrounding mucosa }\end{array}$} \\
\hline
\end{tabular}

Fig. 2. Description of visible dysplasia on colonoscopic surveillance of patients with inflammatory bowel disease. 
Before endoscopic resection of dysplasia in IBD, the endoscopist should assess the size, location, morphology, border, surface features, and background mucosa of the lesion. The morphology is assessed on the basis of the Paris classification and should be determined whether the lesion has a depressed component or dominant nodule. Depressed-type lesions have a prominent tendency to show an invasive cancer, and dominant nodules $(>10 \mathrm{~mm})$ were reported to be a predictor of submucosal invasion. ${ }^{23}$ Delineation of the lesion border is essential to complete endoscopic resection. Endoscopic resection should be performed for a well-demarcated lesion with a discrete border and distinguished from the surrounding mucosa. Surface features such as pit pattern, capillary pattern, and ulceration also should be assessed. Magnifying endoscopy with or without chromoendoscopy facilitates pit pattern assessment. With careful inspection, pit patterns can distinguish neoplastic from inflammatory areas. Furthermore, the type $\mathrm{V}$ pit pattern (non-structured pits) is subclassified into type $V_{I}$, tumors with an irregular glandular structure, and type $V_{N}$, tumors with a clear amorphous area. Type $V_{I}$ is an index for adenoma with severe atypia or potential submucosal invasion, and type $\mathrm{V}_{\mathrm{N}}$ is an index for carcinoma with deep submucosal invasion. ${ }^{24}$ Narrow band imaging (NBI) can visualize the microvascular architecture in the mucosal surface layer with high sensitivity, and the capillary pattern can be categorized. NICE type 3 or Sano's microvascular pattern type IIIB (nearly avascular or loose microcapillary vessels) is an index for deep submucosal invasive cancer. ${ }^{25,26}$ Ulceration on the surface of a lesion is suggestive of submucosal invasion. Even in the absence of such invasion, ulceration can induce deep submucosal fibrosis and complicate endoscopic resection. Detailed consideration should be given to the assessment of the surface characteristics of lesions and, adjunctive imaging techniques such as magnifying endoscopy, NBI, high-frequency endoscopic ultrasonography, and confocal laser endomicroscopy can be useful to determine resectability. In practice, the non-lifting sign (the lesion does not lift in spite of submucosal injection) is used to assess the suitability of colorectal polyps for endoscopic mucosal resection (EMR). The non-lifting sign is thought to be indicative of massive submucosal fibrosis or submucosal invasive cancer. On the basis of the endoscopic assessment of a lesion, an endoscopist can determine whether the lesion is endoscopically resectable or not. Lesions with a type $\mathrm{V}_{\mathrm{N}}$ pit pattern, NICE type 3, ulceration, or lesion with the non-lifting sign is not suitable for endoscopic resection.

In addition to the assessment of endoscopic resectability, whether endoscopic resection is the appropriate option for the patient must be determined. Colectomy is a traditional therapeutic option for the management of dysplasia in IBD.
The risk and benefits related with endoscopic resection and subsequent surveillance in comparison with those of colectomy must be carefully discussed with patients. Surgical resection might be required in dysplastic lesions within the colitis polyposa (numerous inflammatory polyps often with mucosal bridges may prevent effective evaluation) and when the patient lifetime risk of CRC is high.

Lastly, the operating endoscopist must have the experience and skill to perform endoscopic resection of dysplasia in IBD. Endoscopic resection of dysplasia in an area of known colitis is problematic because of inflammation and scarring. To achieve complete resection, en bloc resection is preferred because of histological evaluation, and the specific polypectomy technique such as endoscopic submucosal dissection (ESD) can be required frequently depending on the nature of the lesion. The most important strategy is to maximize the potential of complete removal at the first attempt. If necessary, the patient might be referred to an expert with experience in endoscopic therapy for IBD-associated dysplasia. ${ }^{27}$

\section{MANAGEMENT OF ENDOSCOPICALLY VISIBLE DYSPLASIA}

Most dysplasias detected in IBD are endoscopically visible, and approximately $89 \%$ of dysplasias were elevated. ${ }^{28}$ The United States and European guidelines recommend an endoscopic resection strategy for visible polypoid dysplasia in selected patients. ${ }^{11,29}$ When a dysplasia can be removed safely and completely by endoscopic resection, colectomy need not be recommended to the patient and surveillance should be continued. Endoscopically resectable dysplasias should fulfill the following criteria. ${ }^{13}$

\section{Distinct border}

A distinct lesion border is one that is discrete and can be distinguished from the surrounding mucosa. Visible dysplasia with an indistinct border and invisible dysplasia are not suitable for endoscopic resection. To identify the border, high-definition endoscopy, chromoendoscopy, and/or NBI can be useful.

\section{Endoscopic complete resection}

Endoscopic complete resection indicates that the lesion appears to be completely removed on visual inspection after endoscopic resection. Endoscopic resection of visible dysplasia in chronic colitis is often difficult because it is complicated by submucosal fibrosis. EMR or ESD is a favorable technique to achieve complete resection of visible dysplasia in IBD. 


\section{Histological complete removal}

Histological examination of the resected specimen is available and consistent with complete removal and free resection margin. En bloc resection is preferable for sufficient histological evaluation. However, when the final pathology reports show the risk of lymph node metastasis, such as poor differentiation, lymphovascular invasion, and tumor budding, additional colectomy should be needed.

\section{No residual lesion}

After complete endoscopic resection, biopsies of the surrounding mucosa of the resection site should be performed to ensure absence of residual dysplasia. No residual lesion means that four-quadrant biopsy specimens from the mucosa immediately adjacent to the resection site are free of dysplasia on histological examination. ${ }^{13}$

\section{ESD IN IBD}

EMR is widely accepted currently as a minimally invasive procedure for treating IBD-associated dysplasia and CRC with a low risk of lymph node metastasis (Fig. 3). This resection technique involves a submucosal injection, followed by resection of the lesion using an endoscopic snare. This procedure is effective, with low complication rates, but large lesions $\geq 20$ $\mathrm{mm}$ in diameter are technically more challenging. Chronic intestinal inflammation can induce significant submucosal fibrosis without invasive dysplasia. EMR might be feasible in these settings, but endoscopic en bloc resection of large, sessile lesions and lesions with submucosal fibrosis is technically difficult, and they are usually resected piecemeal. High shortterm cure rates were observed after piecemeal EMR of such lesions, but the long-term high local recurrence rate ( $10 \%$ to $25 \%$ ) is a potential problem. In addition to the increased risk of local recurrence, the possibility of an incomplete resection also causes some concern in terms of inaccurate histopathological assessment. Surgical resection should be considered in cases of unsatisfactory histopathological assessment of highgrade dysplasia due to the risk of submucosal invasion resulting from piecemeal resection of IBD-associated dysplasia. ${ }^{30} \mathrm{En}$ bloc resections, though, are expected to have lower recurrence rates and allow complete histopathological assessment. In patients with dysplasia demonstrating submucosal fibrosis or large size, ESD or ESD with snaring is a reasonable option and might spare a colectomy.

ESD was developed in Japan in the mid-1990s for en bloc resection of superficial gastrointestinal neoplasia, including large lesions and lesions showing a positive non-lifting sign. ESD represents a significant advancement in therapeutic endoscopy and has a major advantage of achieving a higher en bloc resection rate by submucosal dissection using a special electrosurgical knife. The safety and efficacy of ESD for large colorectal lesions have recently been reported in a systematic
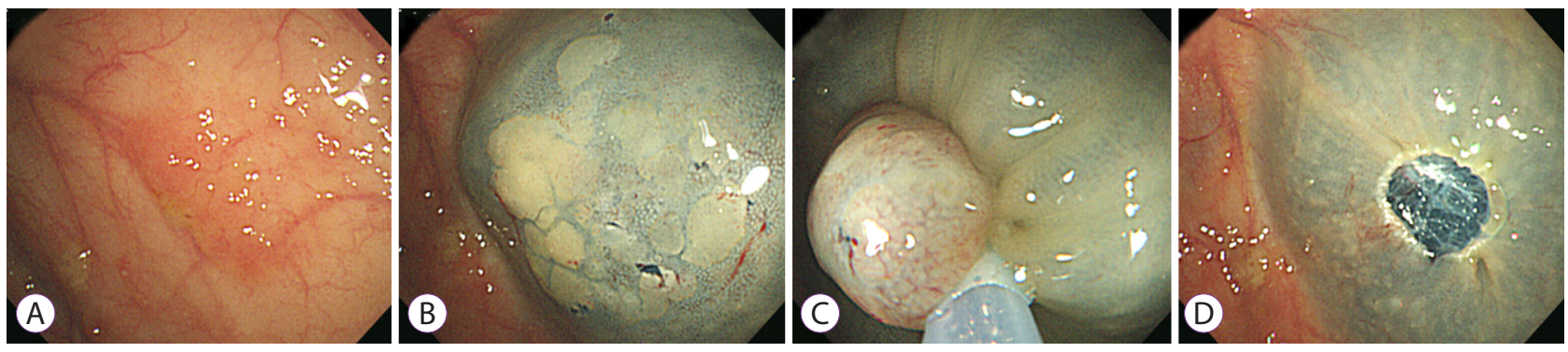

Fig. 3. Endoscopic mucosal resection of dysplasia in ulcerative colitis. (A) A 1.2-cm visible non-polypoid superficial elevated dysplasia. (B) The lesion was lifted after submucosal injection with normal saline mixed with indigo-carmine. (C) Mucosal resection performed using an endoscopic snare. (D) Visible dysplasia resected completely.

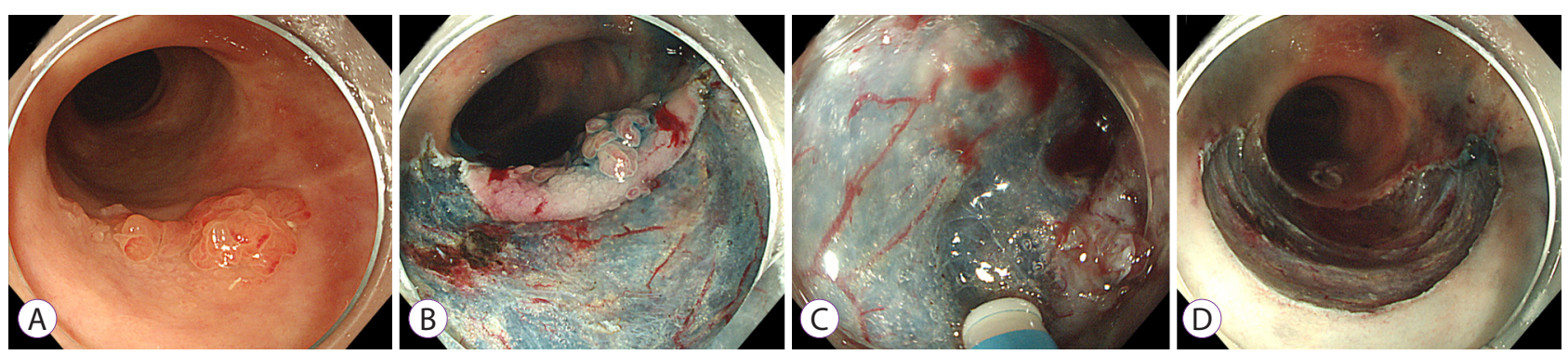

Fig. 4. Endoscopic submucosal dissection of dysplasia in ulcerative colitis. (A) A 2-cm visible polypoid dysplasia. (B, C) Mucosal incision and subsequent submucosal dissection. (D) Visible dysplasia resected completely. 

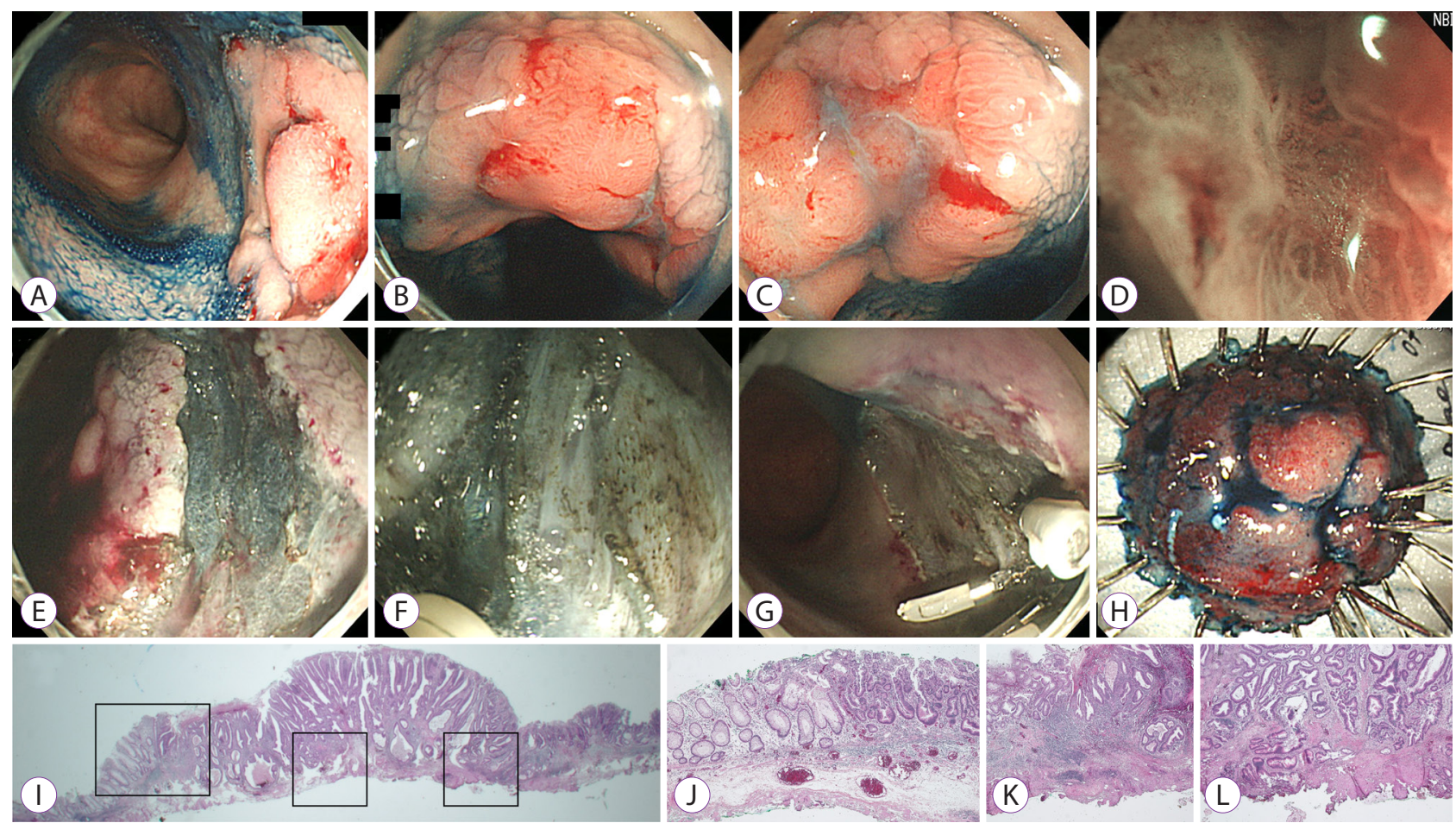

Fig. 5. Endoscopic submucosal dissection of dysplasia in ulcerative colitis. (A) A 2.5-cm sessile polypoid visible dysplasia with a nodular surface feature on the chromoendoscopy. (B) Central nodular area showing a type IIIL pit pattern on magnifying endoscopy. (C, D) A depressive lesion beside the central nodularity, showing a type VI pit pattern on magnifying endoscopy and narrow band imaging. (E) Mucosal incision using a dual knife. (F) Submucosal fibrosis found during submucosal dissection. (G, H) Endoscopic complete resection. (I-L) Pathological examination result showing adenocarcinoma with multifocal submucosal invasion. The maximal depth of the submucosal invasion was $>1,000 \mu \mathrm{m}$, and subsequent colectomy was performed. No residual neoplastic lesion on the endoscopic submucosal dissection site and no lymph node metastasis were observed.

review. $^{31}$

ESD can result in successful en bloc resections even for lesions with submucosal fibrosis, including IBD-associated dysplasia, because endoscopists are able to directly visualize the submucosal layer (Fig. 4). In fact, a highly experienced endoscopist demonstrated excellent curative resections of colorectal ESDs with various devices and accessories for residual/ local recurrence of epithelial lesions after endoscopic resection of severe fibrosis invading the submucosal layer (Fig. 5). ${ }^{32,33}$ ESD in Crohn colitis can be more problematic because of the transmural involvement and frequent fibrosis. ${ }^{34}$

Presently, no data are available to guide when to use EMR and when to use ESD in the context of IBD surveillance. Lesions $\leq 2 \mathrm{~cm}$ in size can generally be treated with snare polypectomy and EMR that permits en bloc resection. Lesions $>2 \mathrm{~cm}$ in size show a higher risk of residual neoplasia on piecemeal resection, and patients with superficial submucosal invasion are candidates for ESD.

However, ESD is not as widely performed in colorectal lesions because of its redundancy, narrow lumen, and thin wall. Specialized training appears to be necessary to acquire a satisfactory and high level of skill for performing ESD. For endoscopists unfamiliar and inexperienced in ESD, ESD with snaring (simplified or hybrid ESD) is an alternative option.

ESD with the snaring technique is performed as follows (Fig. 6): the mucosa around the lesion is incised using an endoscopic knife, followed by partial submucosal dissection to undermine the lesion. When the diameter of the attaching area of the lesion was $<2 \mathrm{~cm}$, the EMR was performed with the snare wire positioned into the groove created by the incision and submucosal dissection. En bloc excision can be achieved for dysplasias $>2 \mathrm{~cm}$ in size or a lesion with submucosal fibrosis. Smith and colleagues recruited 69 patients with selected lesions associated with UC and assessed the technical feasibility of endoscopic resection of visible dysplasia by using ESD with snaring. ${ }^{35}$ Although the procedure has a limitation of selection bias of target lesions, the overall cure rate for the ESD-assisted EMR cohort was 98\% (66/67) at a median of 18 months' follow-up.

\section{FOLLOW-UP OF ENDOSCOPICALLY RESECTABLE DYSPLASIAS}

Patients with an invisible dysplasia characterized by an indistinct lesion border should be treated with colectomy 


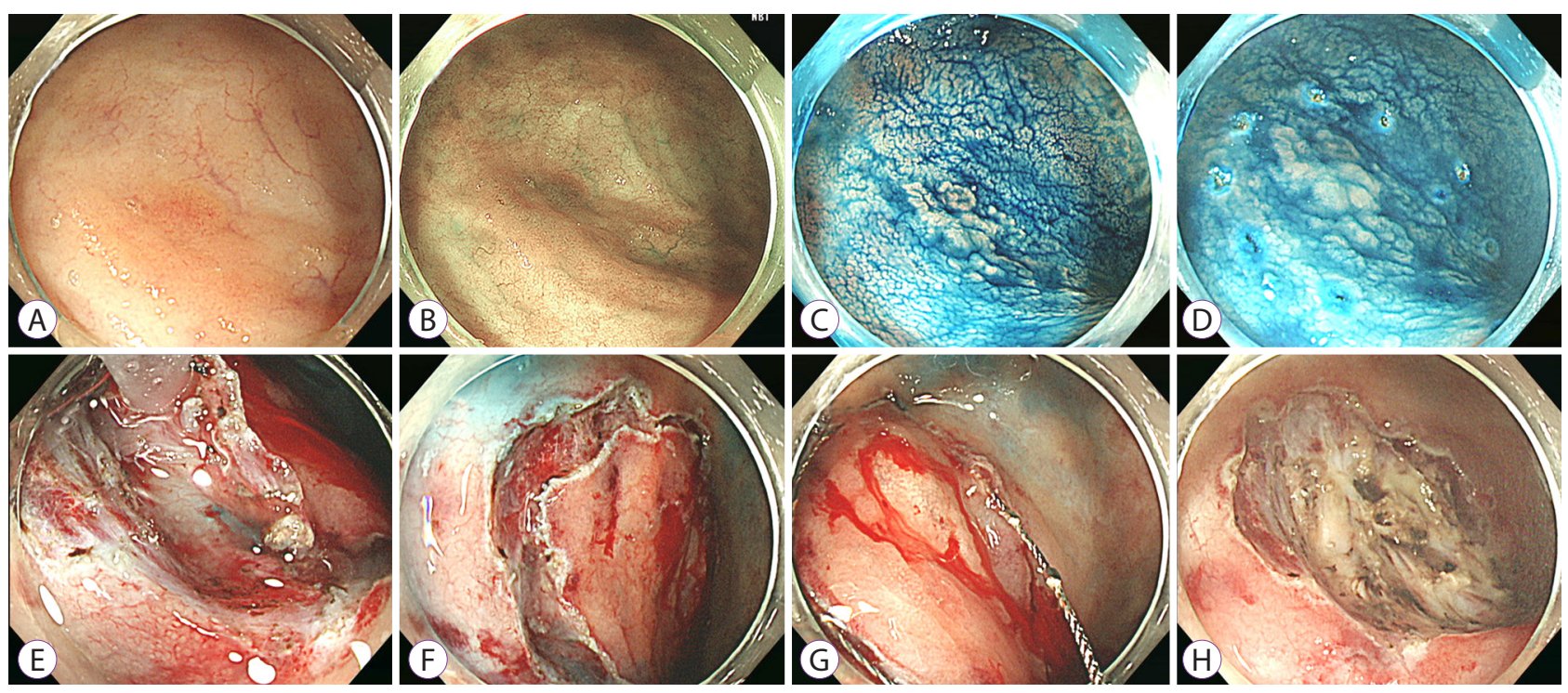

Fig. 6. Endoscopic submucosal dissection with snaring. (A) An approximately $1.5-\mathrm{cm}$ flat non-polypoid visible dysplasia with an indistinct border. (B) The border still indistinct on narrow band imaging. (C, D) The distinct border on chromoendoscopy with indigo-carmine. (E) Submucosal dissection was difficult because of the massive fibrosis. (F) Circumferential mucosal incision. (G) The lesion is snared along with the circumferential groove. (H) Endoscopic submucosal dissection with snaring for dysplasia. The four-quadrant biopsy specimens from the mucosa immediately adjacent to the resection site are free of dysplasia on histological examination.

because of the high association with dysplasia in adjacent flat mucosa and with metachronous or synchronous cancer. By contrast, visible dysplasia can be treated using complete endoscopic resection followed by confirmation of the absence of dysplasia at the margin of the specimen and continued surveillance without surgical intervention based on practice guidelines. ${ }^{1113,36,37}$ Therefore, tattooing after endoscopic resection for dysplasia should be considered to support subsequent surveillance.

In long-term follow-up studies, endoscopically resected polypoid dysplasias in patients with IBD were not associated with an increased future CRC risk as compared with the patients with or without IBD after polypectomy of sporadic adenoma. ${ }^{33,38-47}$ A recent meta-analysis demonstrated a low risk of CRC after endoscopic resection of polypoid dysplasia (pooled incidence, 5.3 cases/1,000 patient-years). ${ }^{33}$ However, the risk of future dysplasia occurrence is increased up to 10fold (pooled incidence of any dysplasia, 65 cases $/ 1,000$ patient-years). ${ }^{33}$ Therefore, close endoscopic surveillance should be performed after endoscopic resection of polypoid dysplasia in IBD. In contrast, long-term follow-up in a non-polypoid dysplasia study is deficient. Only a few studies evaluated more-advanced lesions such as lateral spreading lesions and high-grade dysplasia, and reported high complete resection rates. ${ }^{35,40}$ Non-polypoid dysplasia might be indicated for surveillance if complete resection is achieved.

Surveillance intervals after endoscopic resection of IBD-associated dysplasia are unclear. Surveillance intervals should be tailored to the individualized risk profile. The European
Crohn's and Colitis Organisation guideline recommends intervals of 3-4 years in low-risk patients with IBD but 1-2 years in high-risk patients with IBD (who have at least three of the following conditions: pancolitis, active endoscopic or histologic inflammation, pseudopolyps, and a family history of CRC). ${ }^{48}$ Annual colonoscopy for 5 years is recommended for patients with visible dysplasia and complete resection. High-definition endoscopy with a dye-spraying chromoendoscopy technique for targeted biopsies might represent the first choice in surveillance. When performing surveillance with a standard-definition colonoscopy, chromoendoscopy should be considered. ${ }^{13}$ High-definition endoscopy with NBI is considered an alternative; however, NBI is not suggested in place of white-light colonoscopy.

\section{CONCLUSIONS}

The paradigm for colonoscopic surveillance and endoscopic management of dysplasia in patients with IBD has been shifting. High-definition endoscopy with dye-spraying chromoendoscopy is recommended to allow high-quality visual inspection of the colonic mucosa in patients with IBD. Most dysplasias detected in IBD are endoscopically visible, the border of dysplasia can be delineated, and targeted biopsies are subsequently performed on areas suspicious for dysplasia. Endoscopic resections using the EMR technique can remove endoscopically resectable suspicious lesions $<2 \mathrm{~cm}$ in size. The role of ESD may become important in the management of 
dysplasias $>2 \mathrm{~cm}$ in size or a lesion with submucosal fibrosis. After complete removal of endoscopically resectable polypoid and non-polypoid dysplastic lesions, surveillance colonoscopy is recommended rather than colectomy. When the lesion is not endoscopically resectable, and indistinct dysplasia at the base of the resected lesion, invisible high-grade dysplasia, or multifocal low-grade dysplasia remains, colectomy should be recommended. Evidence for the appropriate therapeutic approach with endoscopy for dysplasia in IBD is limited, and dedicated specialized endoscopists with IBD experience are needed to fully evaluate the recent emerging techniques and technologies to improve the outcomes in IBD patients with dysplasia.

\section{Conflicts of Interest}

The author has no financial conflicts of interest.

\section{REFERENCES}

1. Ekbom A, Helmick C, Zack M, Adami HO. Ulcerative colitis and colorectal cancer. A population-based study. N Engl J Med 1990;323:12281233.

2. Ekbom A, Helmick C, Zack M, Adami HO. Increased risk of large-bowel cancer in Crohn's disease with colonic involvement. Lancet 1990;336:357-359.

3. Söderlund S, Brandt L, Lapidus A, et al. Decreasing time-trends of colorectal cancer in a large cohort of patients with inflammatory bowel disease. Gastroenterology 2009;136:1561-1567; quiz 1818-1819.

4. Bernstein CN, Blanchard JF, Kliewer E, Wajda A. Cancer risk in patients with inflammatory bowel disease: a population-based study. Cancer 2001;91:854-862.

5. Jess T, Simonsen J, Jørgensen KT, Pedersen BV, Nielsen NM, Frisch M. Decreasing risk of colorectal cancer in patients with inflammatory bowel disease over 30 years. Gastroenterology 2012;143:375-381.el; quiz el3-el4.

6. Jess T, Rungoe C, Peyrin-Biroulet L. Risk of colorectal cancer in patients with ulcerative colitis: a meta-analysis of population-based cohort studies. Clin Gastroenterol Hepatol 2012;10:639-645.

7. Devroede G, Taylor WF. On calculating cancer risk and survival of ulcerative colitis patients with the life table method. Gastroenterology 1976;71:505-509.

8. Matkowskyj KA, Chen ZE, Rao MS, Yang GY. Dysplastic lesions in inflammatory bowel disease: molecular pathogenesis to morphology. Arch Pathol Lab Med 2013;137:338-350.

9. Lutgens MW, van Oijen MG, van der Heijden GJ, Vleggaar FP, Siersema PD, Oldenburg B. Declining risk of colorectal cancer in inflammatory bowel disease: an updated meta-analysis of population-based cohort studies. Inflamm Bowel Dis 2013;19:789-799.

10. Magro F, Gionchetti P, Eliakim R, et al. Third European evidence-based consensus on diagnosis and management of ulcerative colitis. Part 1: definitions, diagnosis, extra-intestinal manifestations, pregnancy, cancer surveillance, surgery, and ileo-anal pouch disorders. J Crohns Colitis 2017;11:649-670.

11. Farraye FA, Odze RD, Eaden J, et al. AGA medical position statement on the diagnosis and management of colorectal neoplasia in inflammatory bowel disease. Gastroenterology 2010;138:738-745.

12. Rutter MD, Saunders BP, Wilkinson KH, Kamm MA, Williams CB, Forbes A. Most dysplasia in ulcerative colitis is visible at colonoscopy. Gastrointest Endosc 2004;60:334-339.
13. Laine L, Kaltenbach T, Barkun A, McQuaid KR, Subramanian V, Soetikno R. SCENIC international consensus statement on surveillance and management of dysplasia in inflammatory bowel disease. Gastroenterology 2015;148:639-651.e28.

14. Leedham SJ, Graham TA, Oukrif D, et al. Clonality, founder mutations, and field cancerization in human ulcerative colitis-associated neoplasia. Gastroenterology 2009;136:542-550.e6.

15. Issa JP, Ahuja N, Toyota M, Bronner MP, Brentnall TA. Accelerated age-related CpG island methylation in ulcerative colitis. Cancer Res 2001;61:3573-3577.

16. Lyda MH, Noffsinger A, Belli J, Fischer J, Fenoglio-Preiser CM. Multifocal neoplasia involving the colon and appendix in ulcerative colitis: pathological and molecular features. Gastroenterology 1998;115:15661573.

17. Graham TA, McDonald SA, Wright NA. Field cancerization in the GI tract. Future Oncol 2011;7:981-993.

18. Marcellin P, Gane E, Buti M, et al. Regression of cirrhosis during treatment with tenofovir disoproxil fumarate for chronic hepatitis B: a 5-year open-label follow-up study. Lancet 2013;381:468-475.

19. Blackstone MO, Riddell RH, Rogers BH, Levin B. Dysplasia-associated lesion or mass (DALM) detected by colonoscopy in long-standing ulcerative colitis: an indication for colectomy. Gastroenterology 1981;80:366374.

20. ASGE Technology Committee. High-definition and high-magnification endoscopes. Gastrointest Endosc 2014;80:919-927.

21. Odze R. Diagnostic problems and advances in inflammatory bowel disease. Mod Pathol 2003;16:347-358.

22. Soetikno R, Kaltenbach T, McQuaid KR, et al. Paradigm shift in the surveillance and management of dysplasia in inflammatory bowel disease (West). Dig Endosc 2016;28:266-273.

23. Imai K, Hotta K, Yamaguchi Y, et al. Should laterally spreading tumors granular type be resected en bloc in endoscopic resections? Surg Endosc 2014;28:2167-2173.

24. Kudo S, Kashida H, Tamura T, et al. Colonoscopic diagnosis and management of nonpolypoid early colorectal cancer. World J Surg 2000;24:1081-1090.

25. Hayashi N, Tanaka S, Hewett DG, et al. Endoscopic prediction of deep submucosal invasive carcinoma: validation of the narrow-band imaging international colorectal endoscopic (NICE) classification. Gastrointest Endosc 2013;78:625-632.

26. Ikematsu H, Matsuda T, Emura F, et al. Efficacy of capillary pattern type IIIA/IIIB by magnifying narrow band imaging for estimating depth of invasion of early colorectal neoplasms. BMC Gastroenterol 2010;10:33.

27. American Society for Gastrointestinal Endoscopy Standards of Practice Committee, Shergill AK, Lightdale JR, et al. The role of endoscopy in inflammatory bowel disease. Gastrointest Endosc 2015;81:1101-1121.e1e13.

28. Rubin DT, Rothe JA, Hetzel JT, Cohen RD, Hanauer SB. Are dysplasia and colorectal cancer endoscopically visible in patients with ulcerative colitis? Gastrointest Endosc 2007;65:998-1004.

29. Mowat C, Cole A, Windsor A, et al. Guidelines for the management of inflammatory bowel disease in adults. Gut 2011;60:571-607.

30. Uraoka T, Parra-Blanco A, Yahagi N. Colorectal endoscopic submucosal dissection: is it suitable in western countries? J Gastroenterol Hepatol 2013;28:406-414

31. Repici A, Hassan C, De Paula Pessoa D, et al. Efficacy and safety of endoscopic submucosal dissection for colorectal neoplasia: a systematic review. Endoscopy 2012;44:137-150.

32. Kuroki Y, Hoteya S, Mitani T, et al. Endoscopic submucosal dissection for residual/locally recurrent lesions after endoscopic therapy for colorectal tumors. J Gastroenterol Hepatol 2010;25:1747-1753.

33. Wanders LK, Dekker E, Pullens B, Bassett P, Travis SP, East JE. Cancer risk after resection of polypoid dysplasia in patients with longstanding ulcerative colitis: a meta-analysis. Clin Gastroenterol Hepatol 2014;12:756-764 
34. Iacucci M, Uraoka T, Fort Gasia M, Yahagi N. Novel diagnostic and therapeutic techniques for surveillance of dysplasia in patients with inflammatory bowel disease. Can J Gastroenterol Hepatol 2014;28:361370 .

35. Smith LA, Baraza W, Tiffin N, Cross SS, Hurlstone DP. Endoscopic resection of adenoma-like mass in chronic ulcerative colitis using a combined endoscopic mucosal resection and cap assisted submucosal dissection technique. Inflamm Bowel Dis 2008;14:1380-1386.

36. Leighton JA, Shen B, Baron TH, et al. ASGE guideline: endoscopy in the diagnosis and treatment of inflammatory bowel disease. Gastrointest Endosc 2006;63:558-565

37. Kornbluth A, Sachar DB; Practice Parameters Committee of the American College of Gastroenterology. Ulcerative colitis practice guidelines in adults: American college of gastroenterology, practice parameters committee. Am J Gastroenterol 2010;105:501-523; quiz 524.

38. Jess T, Loftus EV, Jr., Velayos FS, et al. Incidence and prognosis of colorectal dysplasia in inflammatory bowel disease: a population-based study from Olmsted County, Minnesota. Inflamm Bowel Dis 2006;12:669-676

39. Rubin PH, Friedman S, Harpaz N, et al. Colonoscopic polypectomy in chronic colitis: conservative management after endoscopic resection of dysplastic polyps. Gastroenterology 1999;117:1295-1300.

40. Blonski W, Kundu R, Furth EF, Lewis J, Aberra F, Lichtenstein GR. High-grade dysplastic adenoma-like mass lesions are not an indication for colectomy in patients with ulcerative colitis. Scand J Gastroenterol
2008;43:817-820.

41. Goldstone R, Itzkowitz S, Harpaz N, Ullman T. Progression of lowgrade dysplasia in ulcerative colitis: effect of colonic location. Gastrointest Endosc 2011;74:1087-1093.

42. Kisiel JB, Loftus EV Jr, Harmsen WS, Zinsmeister AR, Sandborn WJ. Outcome of sporadic adenomas and adenoma-like dysplasia in patients with ulcerative colitis undergoing polypectomy. Inflamm Bowel Dis 2012;18:226-235.

43. Medlicott SA, Jewell LD, Price L, Fedorak RN, Sherbaniuk RW, Urbanski SJ. Conservative management of small adenomata in ulcerative colitis. Am J Gastroenterol 1997;92:2094-2098.

44. Odze RD, Farraye FA, Hecht JL, Hornick JL. Long-term follow-up after polypectomy treatment for adenoma-like dysplastic lesions in ulcerative colitis. Clin Gastroenterol Hepatol 2004;2:534-541.

45. Pekow JR, Hetzel JT, Rothe JA, et al. Outcome after surveillance of low-grade and indefinite dysplasia in patients with ulcerative colitis. Inflamm Bowel Dis 2010;16:1352-1356.

46. Rozen P, Baratz M, Fefer F, Gilat T. Low incidence of significant dysplasia in a successful endoscopic surveillance program of patients with ulcerative colitis. Gastroenterology 1995;108:1361-1370.

47. Vieth M, Behrens H, Stolte M. Sporadic adenoma in ulcerative colitis: endoscopic resection is an adequate treatment. Gut 2006;55:1151-1155.

48. Harbord M, Eliakim R, Bettenworth D, et al. Third European evidence-based consensus on diagnosis and management of ulcerative colitis. Part 2: current management. J Crohns Colitis 2017;11:769-784. 